\title{
Morfogénesis del sistema reproductor del perro
}

\author{
Vargas, C.V.; Bode, F.F.; Flores Quintana, C.I.
}

Cátedras de Anatomía I e Histología y Embriología, Facultad de Ciencias Veterinarias, Universidad Nacional del Nordeste, Sargento Cabral 2139, Corrientes (3400), Argentina. E-mail: Claudia.vanessa82@gmail.com.

\begin{abstract}
Resumen
Vargas, C.V.; Bode, F.F.; Flores Quintana, C.I.: Morfogénesis del sistema reproductor del perro. Rev. vet. 23: 2, 90-94, 2012. El objetivo del trabajo fue caracterizar la secuencia embrionaria del sistema genital del canino para establecer las etapas del desarrollo y la diferenciación de las gónadas. Para tal fin se trabajó con 20 úteros de los cuales se aislaron embriones en diferentes estadios del desarrollo y se realizó la disección de los mismos, a partir de análisis topográficos y morfológicos. Bajo lupa estereoscópica se caracterizaron las estructuras genitales y se determinaron los estadios donde se produce la diferenciación de la gónada. Se realizaron cortes histológicos de ovarios y testículos teñidos con hematoxilina y eosina, determinándose por microscopia óptica la organización de las gónadas. En los estadios 5 al 7 las crestas genitales se observaron como masas alargadas indiferenciadas en medial del mesonefros. La diferenciación morfológica entre machos y hembras ocurrió a partir del estadio 8. Desde el estadio 9 se notaron cambios de posición de las gónadas debido a la aparición de los metanefros y regresión de los mesonefros. Los genitales externos fueron indiferenciados hasta el estadio 14. La organización histológica mostró que los ovarios presentaron una gruesa corteza con nidos de ovocitos y una médula de tejido conectivo. En los testículos se observó una fina corteza y una medula con cordones testiculares en formación. En el estadio 6 se registró la aparición de los conductos de Müller y Wolff en ambos sexos; la regresión del conducto de Müller en machos se apreció en el estadio 10 y su desaparición en el estadio 14. Las hembras de los estadios 14 presentaron signos de regresión del conducto de Wolff. En general, la especie sigue una línea de desarrollo morfológico semejante a la del resto de los mamíferos. La organización histológica de las gónadas mostró que la formación testicular fue más temprana que la organización ovárica.
\end{abstract}

Palabras claves: perro, desarrollo, cresta genital, ovario, testículo, conductos de Müller y Wolff.

\begin{abstract}
Vargas, C.V.; Bode, F.F.; Flores Quintana, C.I.: Morphogenesis of the dog reproductive system. Rev. vet. 23: 2, 90-94, 2012. The objective of this report was to characterize the sequence of embryonic genital system in dogs to establish the stages of development and differentiation of the gonads. Many embryos at different developmental stages were isolated from twenty uteri. They were dissected, topographically and morphologically analyzed with a stereoscopic microscope in order to determine the gonadal differentiation stage. Tissue sections were taken from ovaries and testes, stained with hematoxylin and eosin and gonad organization was determined by light microscopy. Undifferentiated genital crests in stages 5 to 7 were observed medial to the mesonephros as elongated masses. The morphological differentiation between males and females was observed in stage 8. From stage 9 changes in gonads' position were noted due to metanephros emergence and mesonephros regression. The external genitalia were undifferentiated until stage 14. The histological organization showed that the ovaries had a thick cortex with nests of eggs and a medulla of connective tissue. In the testes a thin cortex and medullar testicular cords in formation were seen. In stage 6 Müller and Wolff ducts appeared in both sexes. In males the müllerian duct's regression was observed in stage 10 and its disappearance on stage 14. In females the Wolff duct showed regression in stage 14. In general, canine specie follows a similar morphological development line as seen in other mammals. Histological organization of the gonads showed earlier testicular differentiation compared to ovary differentiation.
\end{abstract}

Key words: dog, development, genital crests, ovaries, testes, ducts of Müller and Wolff. 


\section{INTRODUCCIÓN}

La organización del sistema reproductor en vertebrados implica una serie de procesos complejos, regulados fundamentalmente por factores genéticos y hormonales. La diferenciación sexual primaria corresponde al desarrollo de las gónadas. En los mamíferos es estrictamente de índole cromosómica, aunque en otros grupos de vertebrados como algunos reptiles y peces, el ambiente y la temperatura son determinantes $18,20,22$. La diferenciación sexual secundaria afecta al fenotipo por fuera de las gónadas e incluye al sistema de conductos genitales masculinos y femeninos así como también a los genitales externos. Estos eventos están controlados por distintas hormonas sexuales, principalmente estrógenos, testosterona, hormona antimülleriana y progesterona ${ }^{12}$.

En los mamíferos, las gónadas se organizan a partir de un par de crestas genitales de posición ventro-medial respecto al riñón mesonéfrico, con el que mantienen una relación topográfica y funcional. Dichas crestas, morfológicamente indiferenciadas, están constituidas por tejido mesenquimatoso laxo rodeado por un epitelio que se extiende hacia la parte interna del mesénquima en forma de cordones sexuales primarios entre los que se ubican las células germinales primordiales (CGP). Las CGP tienen un origen extragonadal: proceden de la base del saco vitelino y pedúnculo alantoideo y migran hacia la cresta genital guiadas por señales quimiotácticas ${ }^{12}$. Una vez establecidas allí, inician un proceso de proliferación y se tornan hiperplásicas, diferenciándose luego en gametogonias ${ }^{9}$.

La diferenciación testicular en los machos se inicia con la formación de los cordones testiculares a partir de los cordones sexuales primarios y la diferenciación morfológica de las células de Sertoli y espermatogonias, así como también la diferenciación de las células de Leydig. Estas últimas comienzan a producir testosterona, hormona que induce la organización del epidídimo, el conducto deferente y las glándulas asociadas, así como la morfogénesis de los genitales externos ${ }^{10}$. En las hembras se produce la degeneración de los cordones sexuales primarios medulares y la diferenciación de un estroma medular vascularizado. En la corteza ovárica se origina una segunda generación de cordones corticales que engloban a las ovogonias y que posteriormente darán origen a las células foliculares ${ }^{10,23}$.

La mayoría de los estudios referidos al desarrollo del sistema reproductor en mamíferos fueron realizados en distintas especies de marsupiales, roedores, artiodáctilos y primates ${ }^{1,3,8,10,13,17,19,24,25}$. En general los trabajos realizados en caninos se han focalizado en el desarrollo general de esta especie ${ }^{5,16,21}$.

En los últimos años, con el advenimiento y desarrollo de técnicas de análisis a nivel celular y molecular, muchos estudios se focalizaron en la investigación de los procesos de regulación y el control de la determinación sexual ${ }^{4,7,15,26,27,28}$, opacando los estudios de índole histomorfológica. Asimismo, en el sistema reproduc- tor, el desarrollo gonadal resulta un buen modelo para estudiar los eventos de diferenciación y organización celular durante la organogénesis ${ }^{2}$.

El objetivo de este trabajo fue analizar los eventos morfológicos implicados en la formación de ovarios y testículos del perro, con el fin de caracterizar el desarrollo gonadal de esta especie de interés veterinario, aún poco estudiada ${ }^{5,16,21}$, determinar los estadios de formación de los esbozos gonadales y de diferenciación sexual, describir la secuencia de eventos del desarrollo de ovarios, testículos y conductos genitales durante la etapa embrionaria y fetal hasta el nacimiento y caracterizar la reorganización histológica gonadal durante la diferenciación de ovarios y testículos.

\section{MATERIAL Y MÉTODOS}

Se seleccionaron 20 úteros provenientes de perras gestantes, obtenidos a partir de ovariohisterectomías. Los úteros grávidos se fijaron en formol al $10 \%$. Se determinó el número de vesículas coriónicas, determinándose 4 a 5 vesículas por cada útero. Se realizó la disección de los úteros grávidos y se aislaron los embriones.

El estadio de los embriones se determinó en referencia a las descripciones realizadas para Felis catus ${ }^{14}$ y la estimación del tiempo de gestación se realizó en base a trabajos anteriores en Canis familiaris ${ }^{21}$.

Se disecaron los embriones de cada estadio para el análisis de la anatomía del sistema reproductor. Las observaciones se realizaron bajo microscopio estereoscópico. Se describieron anatómica y topográficamente los ovarios y testículos, así como los conductos genitales internos y externos.

Para el análisis histológico se extrajeron las gónadas de los embriones y se fijaron en alcohol al $70 \%$ durante 48 horas. Luego se procedió a la aplicación de la técnica histológica clásica, que consiste en la deshidratación en alcoholes e inclusión en parafina. Se realizaron cortes de aproximadamente 10 y 5 micrómetros con micrótomo rotatorio tipo Spencer. Los preparados fueron teñidos con hematoxilina y eosina. Se tomaron fotografías digitales del material observado.

\section{RESULTADOS Y DISCUSIÓN}

Las crestas genitales en los mamíferos aparecen en la superficie ventro-medial de los riñones mesonéfri$\cos ^{8}$. En el perro inicialmente las gónadas son indiferenciadas y el sexo del embrión no se distingue morfológica ni histológicamente hasta después del día 30 de gestación $^{16,21}$. En este trabajo, las crestas genitales se observaron como un par de masas de tejido alargadas, ubicadas ventralmente del borde medial del riñón mesonéfrico, paralelas al plano longitudinal medio (Figura 1). Las mismas se presentaron a partir del estadio 5 ( \pm 20 días de gestación) y se encontraron en estado indiferenciado hasta el estadio 6 ( \pm 30 días de gestación). En estos esbozos gonadales se hallaron inmersas las 


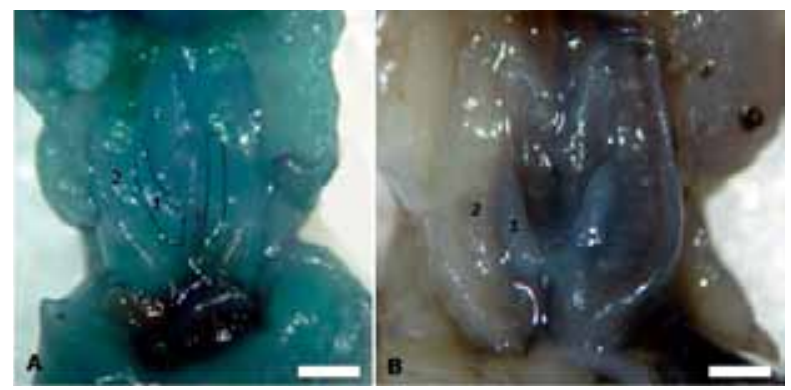

Figura 1. Crestas genitales indiferenciadas. A: estadio 5. B: estadio 6. Ref: 1: Gónada indiferenciada. 2: Riñón mesonéfrico. Escala: $1 \mathrm{~cm}$.

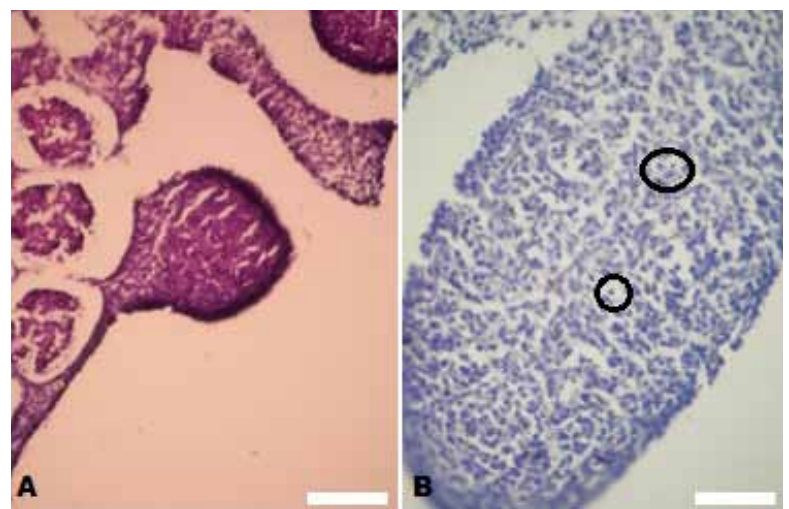

Figura 2. Gónadas indiferenciadas. A: estadio 5, 10x. B: estadio 6, 20x. Círculos negros muestran células germinales primordiales (CGP) inmersas en el tejido gonadal indiferenciado. HyE. Escala: $1 \mathrm{~cm}$.

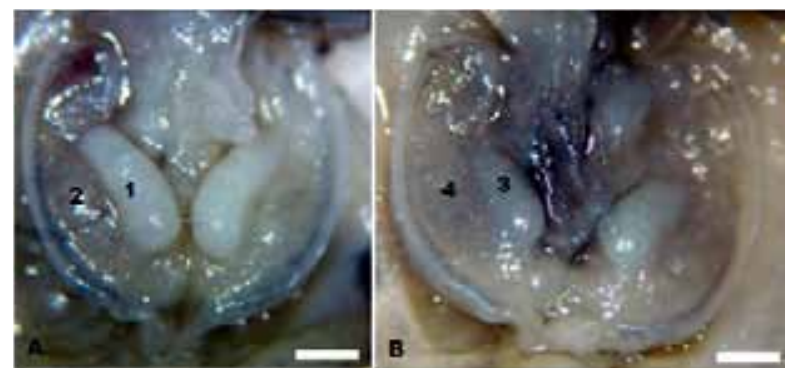

Figura 3. A: Embrión masculino en el estadio 8. B: Embrión femenino en el estadio 8. Ref: 1: testículo. 2: riñón mesonéfrico. 3: ovario. 4: riñones mesonéfricos.

CGP (Figura 2), confirmando observaciones realizadas en otras especies como el ser humano y el bovino ${ }^{8,9,10}$.

A partir del estadio 8, de aproximadamente 36 días, se pudo comprobar una diferenciación morfológica de las gónadas entre ambos sexos (Figura 3). En los estadios 9 al 14, de aproximadamente 36 a 50 días de gestación, se manifestaron cambios a nivel de la ubicación de las gónadas. Además, fue notable la regresión de los mesonefros y el crecimiento de los riñones metanéfricos (Figura 4), tal como fue observado en trabajos realizados por otros investigadores ${ }^{11}$.

Los genitales externos en los estadios 8 al 13 no mostraron diferencias morfológicas entre machos $\mathrm{y}$ hembras (Figura 5, A y B); solo a partir del estadio 14 se observaron diferencias entre los sexos, ya que en el

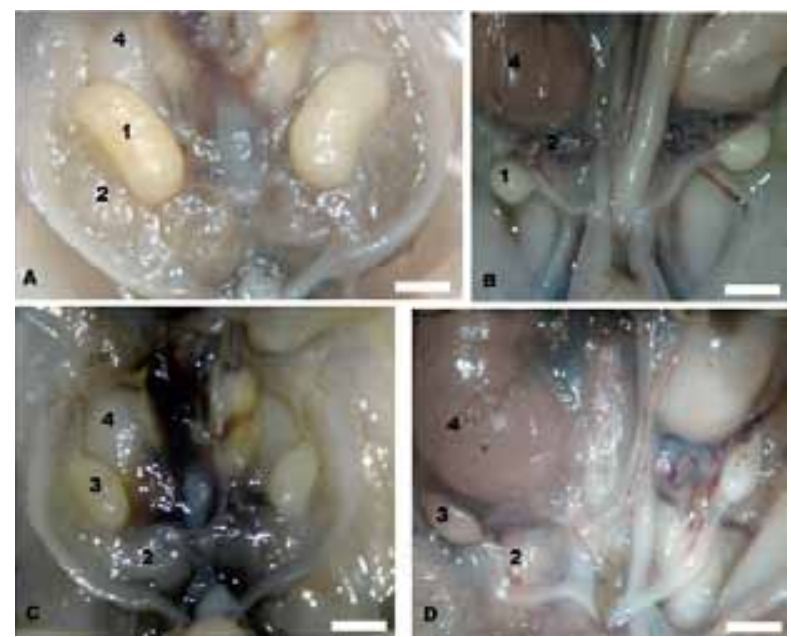

Figura 4. A y B: Embriones masculinos en los estadios 9 y 14. C y D: embriones femeninos en los estadios 9 y 14. Ref: 1: testículos. 2: riñones mesonéfricos. 3: ovarios. 4: riñones metanéfricos. Escala: $1 \mathrm{~cm}$.
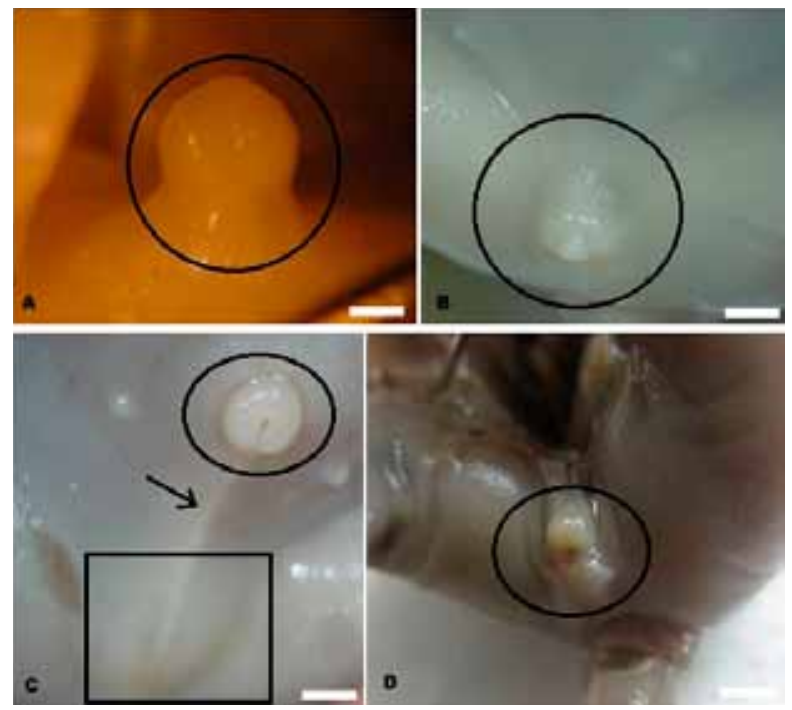

Figura 5: Genitales externos indiferenciados. Ref: A y B: Círculos mostrando los genitales externos indiferenciados en los estadios 8 y 13. C: Macho del estadio 14. El círculo muestra la ubicación de los genitales externos; la flecha indica la ubicación del rafe escrotal y el cuadrado muestra la ubicación de la bolsa escrotal. D: Hembra del estadio 14. El círculo indica la ubicación de los genitales externos. Escala: $1 \mathrm{~cm}$.

macho los genitales externos toman una posición más craneal (Figura 5, C y D). Estos datos son similares a los obtenidos en otros carnívoros ${ }^{6}$.

El análisis histológico de los estadios 8 al 15 mostró la diferenciación de las gónadas en ovarios y testículos. Los ovarios presentaron dos regiones: la médula y la corteza, donde se hallan abundantes CGP, y en estadios más posteriores se observaron agrupamientos de ovogonias rodeadas por células de soporte en la zona cortical (Figura 6, C y D). Los testículos también mostraron dos regiones: una médula con cordones medulares donde se hallaban las CGP y células de sostén, y 


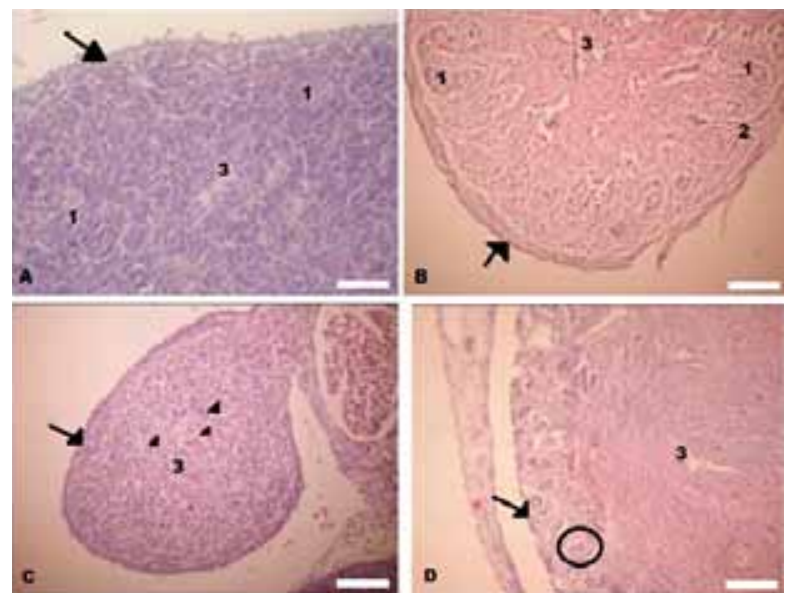

Figura 6. A: Testículo del estadio 8 (40x). B: testículo del estadio 15 (20x). C: ovario del estadio 8 (10x). D: ovario del estadio 15 (20x). Ref: 1: cordones testiculares en formación. 2: tabiques de tejido conectivo. 3: médula. Flechas negras mostrando corteza. Cabeza de flechas mostrando CGP. Circulo negro marcando un nido de ovocitos. HyE. Escala: $1 \mathrm{~cm}$.

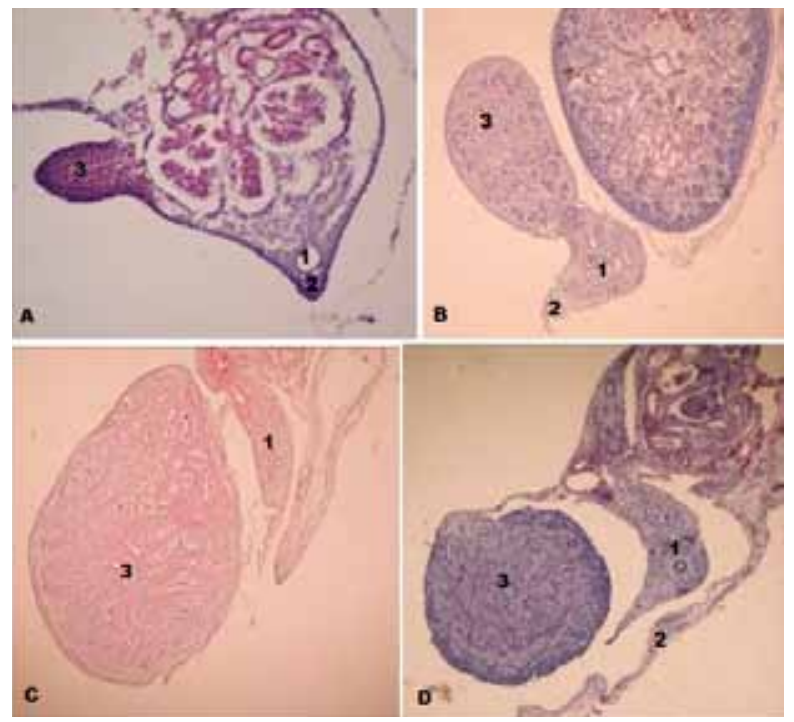

Figura 7. Cortes histológicos de sistema urogenital en diferentes estadios. Ref: A: estadio 6 macho, 5x. B: estadio 10 macho, 5x. C: estadio 15 macho, 5x. D: estadio 14 hembra, 5x. 1: conducto de Wolff. 2: conducto de Müller. 3: gónadas. HyE.

una corteza menos compacta. Posteriormente, se evidenció la organización de los túbulos seminíferos, que presentaron lumen cerrado rodeado por los cordones medulares y abundante tejido intersticial (Figura $6 \mathrm{~A}$ y B). Estos resultados condicen con los reportados en roedores, bovinos y primates $7,9,10,23,28$.

En los estadios 14 y 15, correspondientes a los 50-60 días de gestación, en las gónadas femeninas se destacó la presencia de nidos de ovocitos y algunos folículos primordiales (Figura 6, D), a diferencia de lo que sucede en roedores, en donde la foliculogénesis se produce después del nacimiento ${ }^{7}$.
El conducto de Müller se presentó a partir del estadio 6 (25-30 días aproximadamente); los primeros signos de involución del mismo en el macho se observaron en el estadio 10 (36 días aproximadamente) y la desaparición total del mismo se visualizó en el estadio 15 (45-50 días aproximadamente). En el estadio 14 de las hembras, el conducto de Wolff se observó como un grupo de células alrededor de un orificio obliterado (Figura 7). Estos datos coinciden con los presentados en un estudio realizado sobre la regresión del conducto de Müller en perros ${ }^{16}$.

Los resultados obtenidos revelaron que el canino sigue una trayectoria de desarrollo morfológico semejante a la del resto de los mamíferos. En referencia a la organización histológica de las gónadas, la formación de los testículos fue más temprana que la organización ovárica. Estos hallazgos abren nuevos interrogantes acerca del mecanismo de desarrollo de las gónadas en Canis familiaris, la diferenciación a partir de un estado indiferente, la caracterización de los eventos ontogenéticos en la gametogénesis durante el periodo embrionario-fetal, la identificación del "onset" de la meiosis y el establecimiento de las etapas en cada evento de la gametogénesis.

\section{REFERENCIAS}

1. Arey LB. 1964. Anatomía del desarrollo (embriología): tratado y manual de laboratorio, $5^{\circ} \mathrm{ed}$, Vazquez Ed, Buenos Aires, p. 22-26.

2. Bristol-Gould S, Woodruff T. 2006. Folliculogenesis in the domestic cat (Felis catus). Theriogenology 66: 5-13.

3. Carlson BM. 1988. Embriología básica de Patten, $5^{\circ}$ ed, Interamericana, México, p. 475-478.

4. Chaboissier MC, Kobayashi A, Vidal VI, Lützkendorf S, Van de Kant HJ, Wegner M, Rooij DG, Behringer RR, Schedl A. 2004. Functional analysis of Sox8 and Sox 9 during sex determination in the mouse. Development 131: 1891-1901.

5. Cunha GN, Jacomini JO, Beletti ME. 2005. Taxa de fertilizacao e desenvolvimento embrionário inicial em femeas caninas (Canis familiaris-Linnaeus, 1758). Biotemas 18 : 155-167.

6. Cunha GR, Place NJ, Baskin L, Conley A, Weldele M, Cunha TJ, Wang YZ, Cao M, Glickman SE. 2005. The ontogeny of the urogenital system of the spotted hyena (Crocuta crocuta Erxleben). Biol Reprod 3: 554-564.

7. De Falco T, Capel B. 2009. Gonad morphogenesis in vertebrates: divergent means to a convergent end. Rev Cell Dev Biol 25: 457-482.

8. Dellmann HD, Brown EM. 1976. Histología veterinaria, Acribia, Zaragoza, p. 343-371.

9. Diniz EG, Esper CR, Jacomini JO, Vieira RC. 2005. Desenvolvimento morfológico dos ovários em embrioes e fetos bovinos da raca Nelore. Arq Bras Med Vet Zootec 1: 70-76.

10. Eynard AR, Valentich MA, Rovasio RA. 2008. Histología y embriología del ser humano: bases celulares y moleculares, $4^{\circ}$ ed, Panamericana, Buenos Aires, p. 519-540. 
11. Gier HT, Marion GB. 1969. Development of mammalian testes and genital ducts. Biol Reprod 1: 1-23.

12. Gilbert SF. 2006. Biología del desarrollo, $7^{\circ}$ ed, Panamericana, Buenos Aires, p. 585-607 y 655-681.

13. Hafez ES. 1989. Reproducción e inseminación artificial en animales, $5^{\circ}$ ed, Interamericana, México, p. 13-29 y 7083.

14. Illanes J, Orellana C, Fertilio B, Leyton V, Venegas F. 2007. Análisis macroscópico y microscópico del desarrollo embrionario y fetal en el gato (Felis catus), en relación con el desarrollo de la vesícula coriónica y de la placenta. Int J Morphol 25: 467-481.

15. MacLaughlin DT, Donahoe PK. 2004. Sex determination and differentiation. New Engl J Med 350: 367-378.

16. Meyers-Wallen VN, Manganaro TF, Kuroda T, Concannon PW, MacLaughlin DT, Donahoe PK. 1991. The critical period for mullerian duct regression in the dog embryo. Biol Reprod 46: 626-633.

17. Moore KL. 1990. Embriología básica, $3^{\circ}$ ed, Interamericana, México, p. 166-178.

18. Morrish BC, Sinclair AH. 2002. Vertebrate sex determination: many means to an end. Reproduction 124: 447-457.

19. Paniagua R, Nistal M. 1983. Introducción a la histología animal comparada, Ed. Labor, Barcelona, p. 180-185.

20. Pieau C, Dorizzi M. 2004. Oestrogens and temperaturedependent sex determination in reptiles: all is in the gonads. J Endocr 181: 367-377.
21. Pretzer SD. 2008. Canine embryonic and fetal development: A review. Theriogenology 70: 300-303.

22. Renfree MB, Shaw G. 2001. Germ cells, gonads and sex reversal in marsupials. Int J Dev Biol 45: 557-567.

23. Sadler TW. 2001. Embriología médica con orientación clínica, $8^{\circ}$ ed, Panamericana, Buenos Aires, p. 294-333.

24. Sánchez A, Von Lawzewitsch I. 1984. Lecciones de embriología veterinaria, $3^{\circ}$ ed, Hemisferio Sur, Buenos Aires, p. 20-40

25. Schwarze E, Schröder L, Michel G. 1970. Compendio de anatomía veterinaria: embriología, Acribia, Zaragoza, p. 50-60

26. Stebler J, Spieler D, Slanchev K, Molyneaux KA, Richter U, Cojocarud V, Tarabykine V, Wyliec C, Kesselb M, Raz E. 2004. Primordial germ cell migration in the chick and mouse embryo: the role of the chemokine SDF-1/ CXCL12. Develop Biol 272: 351-361.

27. Tevosian SG, Albrecht KH, Crispino JD, Fujiwara Y, Eicher EM, Orkin SH. 2002. Gonadal differentiation, sex determination and normal Sry expression in mice require direct interaction between transcription partners GATA4 and FOG2. Development 129: 4627-4634.

28. Wilhelm D, Palmer S, Koopman P. 2007. Sex determination and gonadal development in mammals. Physiol Rev 87: 1-28.

\section{Revista Veterinaria obtuvo el máximo nivel de categorización del CAICYT-CONICET}

Tras el pertinente proceso de evaluación según criterios de calidad editorial, en setiembre de 2005 CAICYT-CONICET ha clasificado a nuestra publicación con Categoría 1 (nivel superior de excelencia), con lo cual pasa a integrar el Catálogo Latindex (folio 14022). La Dirección de Revista veterinaria agradece a quienes colaboraron para obtener tan importante distinción. Ver: http://www.latindex. unam.mx/busquedas/catalogotitulo.html 